\title{
QIRT10

\section{INFRARED THERMOGRAPHY ANALYSIS OF THE EQUIPMENT BENEATH THE CHASSIS OF METROPOLITAN RAILWAY VEHICLES}

\author{
Capote, J. A. ${ }^{1}$, Alvear, D. ${ }^{1}$, Abreu, O. $V^{1}$, Lázaro, M. ${ }^{1}$, Hernando, $J .^{2}$ \\ ${ }^{I}$ Group GIDAI - Fire Safety - Research \& Technology. University of Cantabria \\ Ave. Los Castros, s/n; 39005 Santander (Spain) \\ ${ }^{2}$ IRTECH, S.L. - CDTUC - Center of Technological Development of the University of Cantabria. Ave. \\ Los Castros, s/n; 39005 Santander (Spain)
}

There have been several cases of smoke and fire generation from beneath railway vehicle chassis of metropolitan rail systems, leading to an interruption of their normal use and thus highlighting the need for a higher level of safety for this transport. Therefore, there is a need to develop some form of Fire Protection Equipment that should cover all the elements and equipment located under the vehicle chassis.

This scientific analysis is aimed at obtaining a map of the temperature distribution of the equipment beneath chassis. Passive infrared thermography techniques are used, that allow the prediction of zones in which smoke and fire generation is most probable. This data should be validated through the use of previously tabulated values of the equipment's emissivity.

Thermographic data collection of elements located beneath the chassis was carried out in the workshops immediately after the cars completed their regular service. Measurements were made assuming preliminarily tabulated values of the emissivities of the materials from the elements. These were corroborated by post-processing analysis of thermograms, with appropriate adjustments being made. Corrected thermograms of all the interesting elements were obtained. Fig. 1 shows a schematic of how the thermal images were taken.

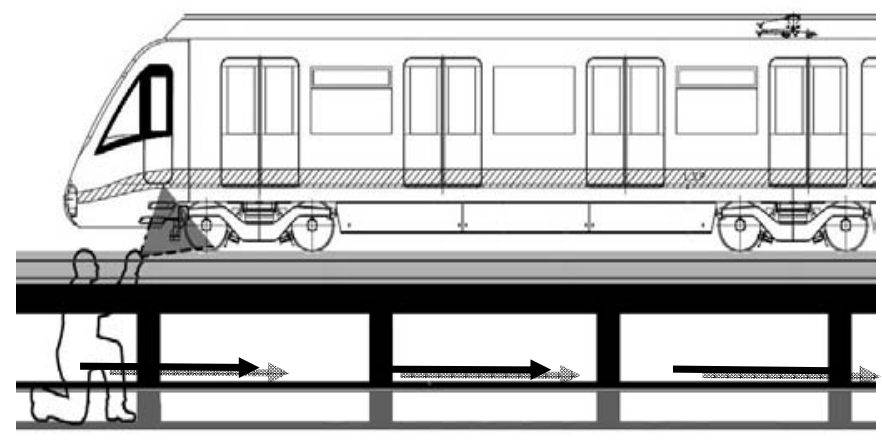

Figure 1 - Side view. Movement of the thermographic slide.

A sample of one of the thermographic images is shown in Fig. 2. They are obtained and corrected using elements with higher temperatures. 

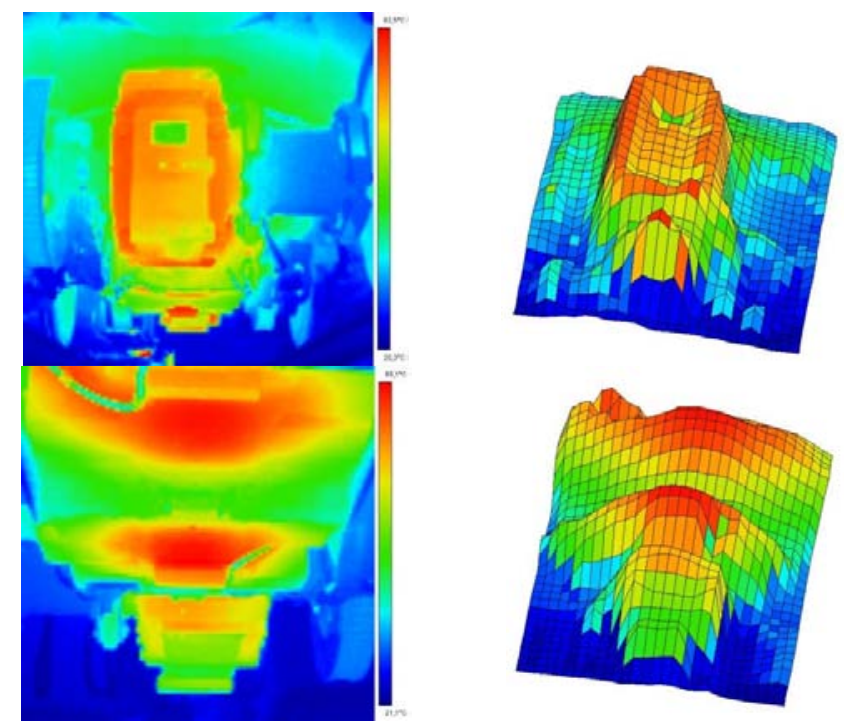

Figure 2 - Elements with higher values of thermic radiation.

Using the thermograms, an analysis was performed of the absolute and relative (with respect to the minimum recorded temperatures) average and maximum temperatures of each element under the chassis. Fig. 3 shows the absolute average temperature map under chassis elements of one of the coaches tested.

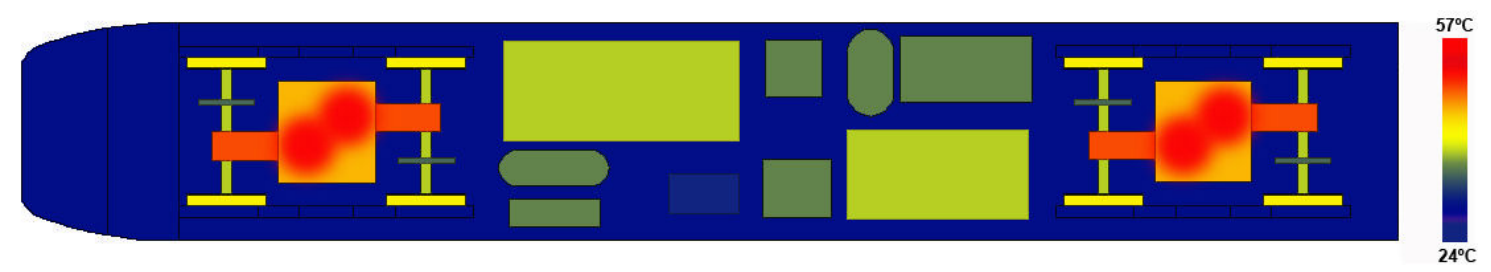

Figure 3 -Distribution of the average temperature values of a coach.

The average and maximum relative temperatures for 20 analysed elements are shown in Fig. 4. The highest values of the average and maximum temperatures were recorded at the front and rear bogies, and on also on the rear bogie connection.

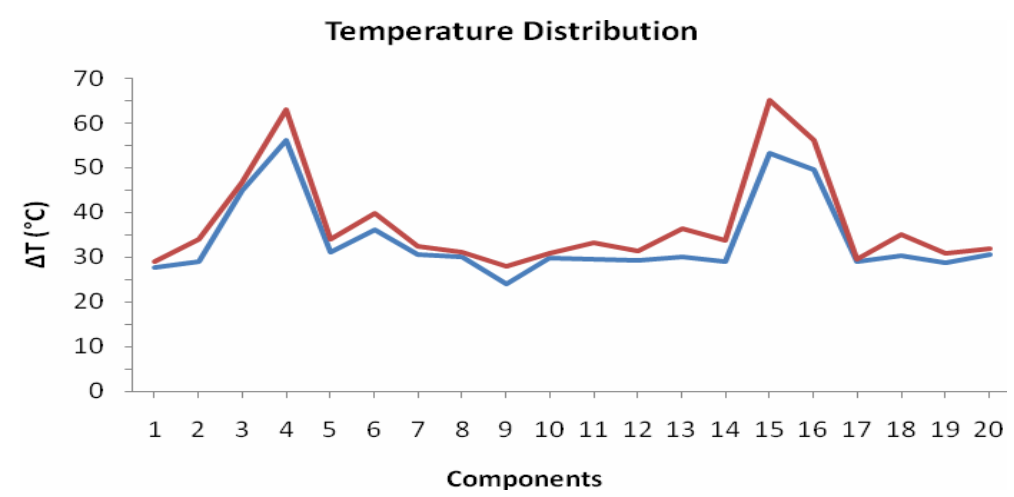

Figure 4-Comparative analysis of the maximum and minimum temperature results of the studied equipment. 